\title{
Key issues regarding interaction of adjacent RC structures
}

\author{
M. J. Favvata \\ Department of Civil Engineering, \\ Democritus University of Thrace, Greece
}

\begin{abstract}
In this study, the key parameters of structural pounding and their influence on the ductility and shear requirements of reinforced concrete structures with different story heights are presented. The examined structures are multistory reinforced concrete $(\mathrm{RC})$ frames with unequal total heights designed according to the codes EC2 and EC8. Results of an extensive investigation in this field indicate that the most vital issues for the seismic response of the RC structures with interaction problems are: the gap distance separation between the adjacent structures, the location of the point of the column that suffers the hit, the difference of the number of stories between the adjacent structures, the local response of the columns that suffer the impact, the local response of the RC beam-column joints at the level of the pounding the existence of masonry infill panels and their response. Each of these parameters is analysed and its importance on the seismic performance of the RC structures is evaluated. Further, initial results based on dynamic step by step analyses have shown that the seismic demand and the level of the seismic hazard are important parameters for the assessment of RC structures with pounding problems. These parameters could be used in the design process in order to eliminate the critically increasing local requirements of the structural members due to the pounding effect. In this view, it seems to be appropriate that the codes provisions for the evaluation of an adequate gap distance between adjacent RC structures take into account the seismic demand and the level of the seismic hazard.

Keywords: structural pounding, shear demands, ductility requirements, gap distance, height variation, infills, beam-column joints, reinforced concrete structure, dynamic step by step analysis, seismic assessment, limit states, seismic hazard.
\end{abstract}




\section{Introduction}

Earthquake induced collisions between adjacent structures have been repeatedly reported in the literature as a usual case of damage. Based on reports of field observations after numerous destructive earthquakes all over the world, it can be concluded that pounding is frequently observed when strong earthquakes strike big cities and densely populated urban areas [1-3]. In these events it has been proved that the interaction between adjacent buildings is a usual cause of damage and moreover there are cases reported in literature that pounding has been identified as a primary cause for the initiation of collapse [3]. In the event of the earthquake that struck Mexico City in 1985, damage due to pounding was identified in over $40 \%$ of 330 severely damaged or collapsed buildings and in $15 \%$ of all cases it led to collapse [2,3]. Although in this respect the earthquake of Mexico City is a unique case in terms of damage and collapse cases attributed to pounding, in all the earthquakes of the last decades structural pounding was always present. Furthermore, a recent survey of seismic separations between buildings for Taipei City [4] reveals that for the 2359 surveying tall buildings 403 are predicted to suffer pounding damage. Among them 46 might collapse and 76 might suffer severe damage. It is emphasized that inter-story pounding which according to the authors it is known to cause instant collapse, would account for 39 of the cases of collapse or $85 \%$ of the total 46 cases.

During the last two decades many analytical investigations have been reported on the problem of the structural pounding. In the beginning these studies were based on the response of pairs or sets of colliding single degree of freedom systems in earthquake excitations. Results indicate that in the case of colliding alike systems in the row, exterior systems tend to suffer more due to the pounding effect than do the interior ones, the latter often experiencing reductions in their response.

Cases of pounding between multi-degree-of-freedom systems have been also examined. The buildings were idealized as lumped mass, shear beam type, multidegree-of-freedom systems with bilinear force-deformation characteristics. The story levels of the colliding structures were always the same. Results of collisions on the response of a 5-story building in configurations of 2, 3 and 4 buildings in contact have been reported [5]. Examination of the pounding effect in cases of two buildings with different number of stories is also included. In situations like these, according to the authors, pounding can be catastrophic.

Numerical formulations for the pounding of two structures focusing primarily on advanced solution techniques have also been reported [6,7]. Maison and Kasai [7] proposed the formulation and the solution of the multiple degree of freedom equations of motion for a type of structural pounding between two buildings and presented the pounding between a tall 15-story structure and a shorter 8-story stiffer and more massive building. Formulation and results are based on elastic dynamic analysis. Chau and Wei [8] have proposed a formulation to model pounding of two adjacent structures under harmonic earthquake excitation as non-linear Hertzian impact between two single-degreeof-freedom oscillators. 
Karayannis and Fotopoulou [9] examined various cases of structural pounding between multistory reinforced concrete structures designed according to the Eurocodes 2 and 8 . The work is based on non-linear dynamic step-by-step analysis and in all the examined cases the story levels of the two colliding structures were always the same.

The effect of soil flexibility on the inelastic seismic response of a particular case of adjacent 12- and 6-story reinforced concrete moment-resisting frames are examined by Rahman et al. [10].

Dynamic response of bridge systems with several simple spans can also experience pounding between adjacent decks [11, 12].

It is emphasized that all the previously mentioned papers examine pounding problems with buildings that have stories with equal inter-story heights and consequently the pounding takes place always between the floor masses of the colliding structures. Moreover, most of the existing analytical studies except from Karayannis and Fotopoulou [9] have yielded conclusions that are not directly applicable to the design of multistory buildings potentially under pounding.

Considering, that (i) pounding is a frequent cause of structural damage that under certain conditions it can lead to collapse initiation, (ii) the problem has not yet been studied effectively especially for the case of colliding structures with non-equal inter-story heights and (iii) according to the new design codes (Eurocodes 2 and 8, ACI 318) flexible frame structures prone to structural pounding can be designed; in this approach an attempt to present key parameters of the structural pounding on the ductility and shear requirements of reinforced concrete structures with different story heights is presented. The examined structures are multistory reinforced concrete frames with unequal total heights and different story heights designed according to the codes EC2 and EC8. In these very common pounding cases the slabs of the diaphragms of the short stiffer structure hit the columns of the other structure at a point within the deformable height. This phenomenon is referred to as inter-story pounding and it can be considered, for obvious reasons, as the most critical case of earthquake induced interaction between adjacent multistory reinforced concrete structures. It is noted that until then, although inter-story pounding is a common case in practice $[1,4]$, it has not been methodically investigated in the literature. Even over the last decade [13-26] most of the studies on the pounding problem have been focused on modeling the floor to floor collision. The majority of the interstory pounding research has been undertaken by Karayannis and Favvata [13, 14], Favvata and Karayannis [16] and Favvata et al. [15, 17, 18] (see also Cole et al. [21]).

\section{Types of structural pounding}

Two distinct types of structural pounding are identified (Figure 1):

(a) Interaction case Type A. The story levels of the two structures have the same height so that collisions may occur between the story diaphragms and consequently between the story masses. 
(b) Interaction case Type B. The heights of the story levels of the two structures are not equal. In this very common case the slabs of the diaphragms of each structure hit the columns of the other structure at a point within the deformable height. This phenomenon is referred to as inter-story pounding. The actual condition and the model idealization of this pounding case are shown in Figure 1. The analysis model used for the pounding area is presented in Figure 2.

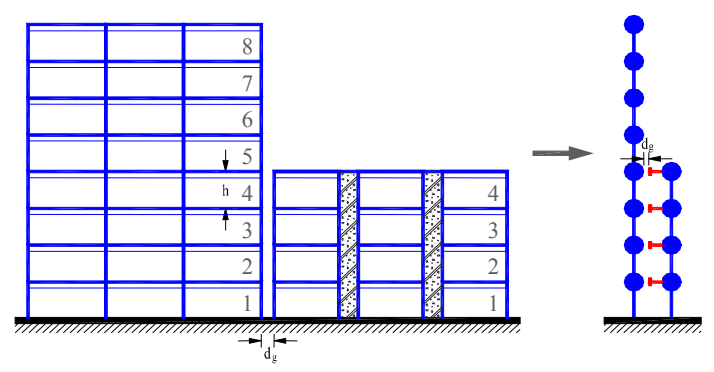

Interaction Type A: Pounding at the floor levels

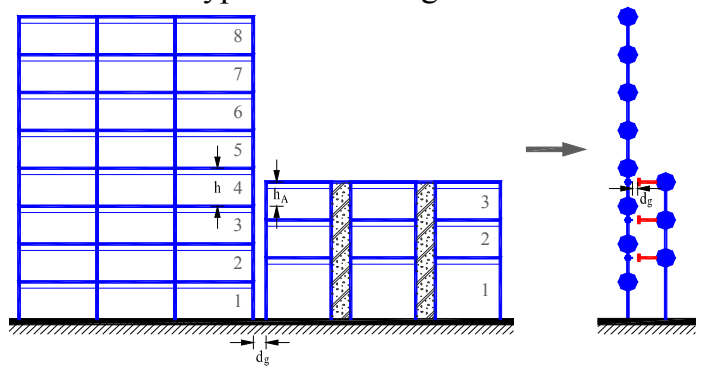

Interaction Type B: Pounding at the columns

Figure 1: Actual condition and model idealization of pounding between adjacent structures.

\section{Key parameters for the interaction problem}

Seventy-two interaction cases of Type A between structures with unequal total heights $[9,13]$ indicated increased ductility requirements of the columns in the pounding area mainly in the cases that the adjacent structures were in contact from the beginning. Nevertheless these requirements do not appear to be critical for all the examined cases $[9,13]$. The most critical interaction case for the seismic performance of the reinforced concrete (RC) multistory frame structures is that of the inter-story pounding Type B [13-17]. In this interaction case of Type B the local response of the columns of the tall structure that suffer the hit of the upper floor slab of the adjacent shorter structure has been verified as the most vital issue for the integrity of the structure.

An extensive investigation on the interaction problem between multistory reinforced concrete frames with unequal total heights and different story heights designed according to the codes EC2 and EC8 has been presented by Karayannis 


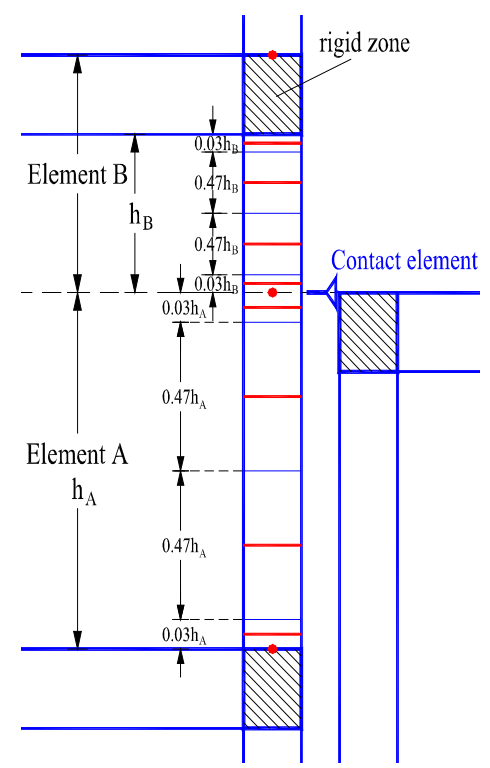

Figure 2: Analysis model for the pounding area.

and Favvata [13, 14, 16] and Favvata et al. [15, 17, 18]. More than one hundred pounding cases, each one for two different seismic excitations, were examined. These cases included the pounding cases of multistory frames with a 3-story structure and a 3-story rigid barrier. Key parameters and their influence on the pounding problem are presented below.

\section{Height variation of adjacent structures}

Four multistory frame structures have been designed [14]; two 8-story frame structures, one 6-story structure and one 12-story structure. Both 8-story frame structures were designed according to Eurocodes 2 and 8, the first one meeting the Ductility Capacity Medium (DCM) criteria and the latter one the Ductility Capacity High (DCH) criteria of these codes. The other two structures were designed according to Eurocodes 2 and 8 too, both meeting the Ductility Capacity Medium (DCM) criteria. Behaviour factors for DCM and DCH frames were $\mathrm{q}=3.75$ and 5.00 , respectively.

From the parametric study reported in Karayannis and Favvata [14], it has been deduced that no safe conclusions can be extracted about the influence of small changes of the number of stories of the tall building on the demands for ductility and shear strength of the columns that suffer the hit. High increase, though, of the number of stories of the tall building (from 6 to 12 stories) in all the examined pounding cases has decreased substantially the demands for ductility and shear strength of the columns that suffer the hit (Figs 3, 4 and 5).

\section{Gap distance between the adjacent structures}

It has been observed that the ductility demands for the column that suffers the pounding hit are substantially increased comparing with the ones when 

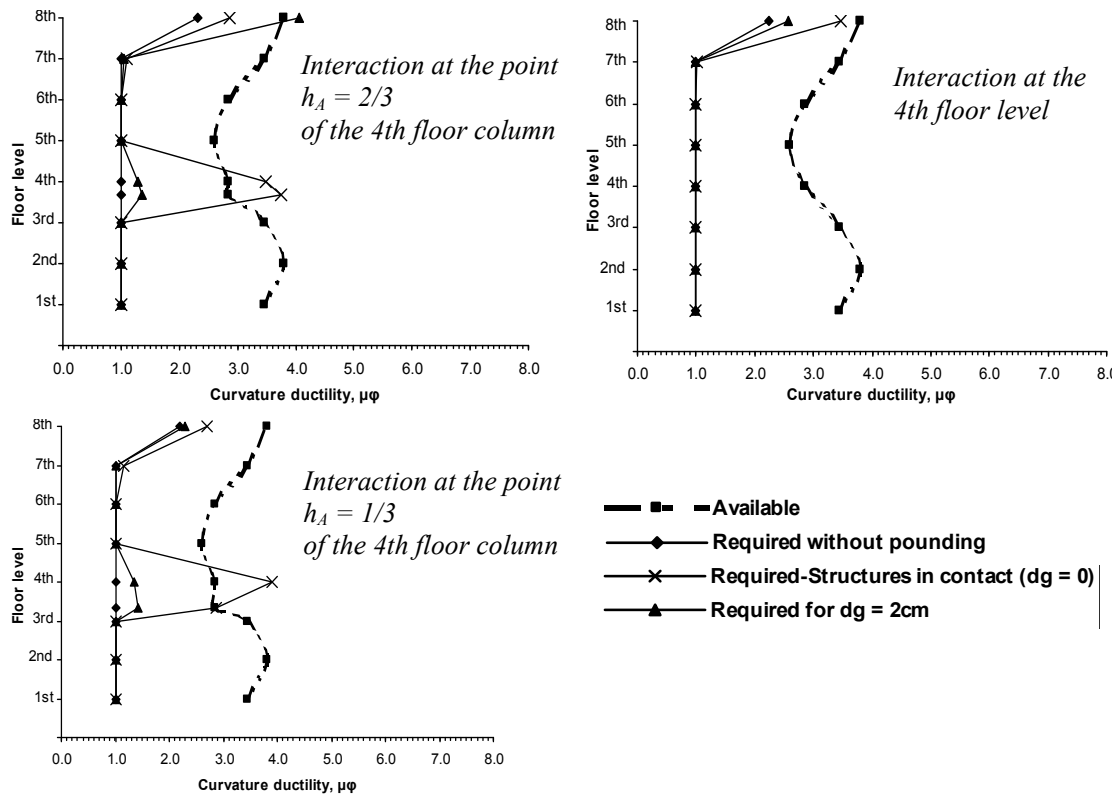

Figure 3: Interaction between the 8-story DCM frame and a 3-story structure. Ductility requirements of the external reinforced concrete columns at the pounding side of the 8-story frame.

the structure vibrates without the pounding effect. In the cases that the two buildings are in contact these demands appear to be critical since they are higher than the available ductility values. In the cases that there is a small gap distance $\left(\mathrm{d}_{\mathrm{g}}=2 \mathrm{~cm}\right)$ between the interacting buildings the ductility demands of this column are also higher than the ones of the same column when the structure vibrates without the pounding effect but they appear to be lower than the available ductility values (Fig. 3). It has to be stressed that in all the examined cases the observed shear forces of the critical part of the column that suffers the impact, exceed the shear strength of the column (Figs 4 and 5).

In general, the existence of a gap between the adjacent structures decreases drastically the high ductility demands of the columns that suffer the hit but it is not equally effective in decreasing the developing shear forces due to the pounding.

\section{Location of the column point that suffers the hit}

The examined cases included pounding cases between an 8-story structure and a 3 -story frame-wall structure or a rigid barrier [15]. Five positions of the contact point are considered in order to study the influence of the exterior joints local damage on the seismic behaviour of the critical column that suffers the hit. The examined positions were at the points $\mathrm{h}_{\mathrm{A}}$ (see also Fig. 3): 1/6, 1/3, 1/2, 2/3 and $5 / 6$ of the interstory height of the column of 4 th floor of the 8 -story frame. The results of this study showed that changes on the position that the impact takes 

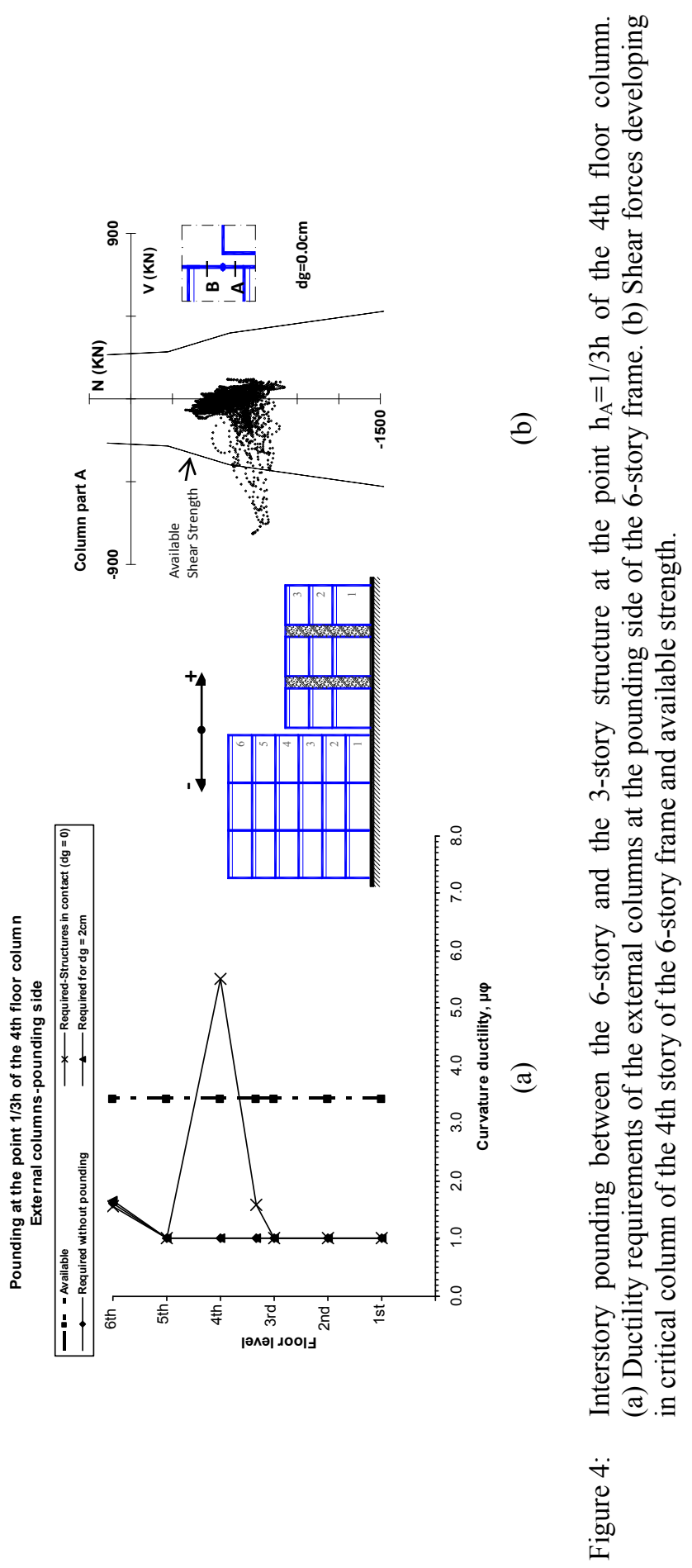
place within the deformable height of the column and changes on the initial gap distance between the adjacent structures yielded different requirements for flexural capacity of the critical column.

\section{Influence of the RC joints behavior on the pounding problem}

Another key parameter that has been repeatedly identified as leading cause of failure and eventual collapse of reinforced concrete buildings is the local damage of the $\mathrm{RC}$ exterior joints due to insufficient reinforcement inside the core area [28].

Thus in 2009, Favvata et al. [15] investigated the effect of the RC beamcolumn joints strength and stiffness degradation on the seismic response of a multistory RC frame structure that suffers the inter-story structural pounding. In order to incorporate the influence of the joints local damage effect on the examined inter-story pounding cases, a special purpose element is employed in the finite analysis mesh of the structural systems. The enhanced joint element is a spring element with zero length that it is defined by two nodes with the same coordinates, and it is only influenced by the relative rotational displacements between the nodes. More details can be found in Favvata et al. [27].
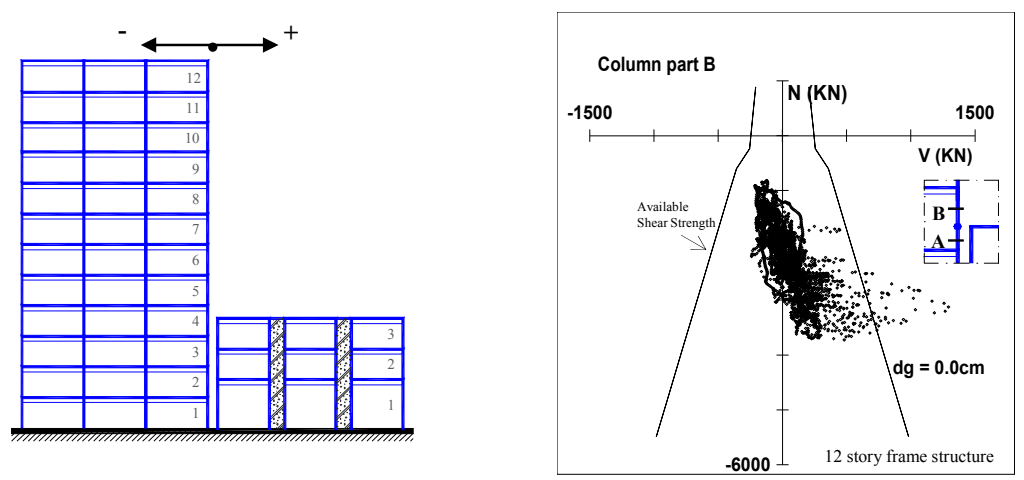

Figure 5: Shear forces developing in critical column of the 4th story of the 12story frame due to the interaction with the 3-story structure at the point $h_{A}=2 / 3 h$ and available strength.

Two types of beam-column joints behaviour were considered: (a) all exterior joints are considered with reduced capacity and simulated using the recently proposed model, and (b) all the joints are assumed as rigid ones. The design of the examined RC buildings was based on the concept that they represent existing buildings without major design deficiencies except for the lack of adequate shear reinforcement in the joints [15].

The fundamental periods of the examined structures for the case with the joint effect are presented in Figure 6 along with the elastic response spectrums of the selected earthquake records: El Centro - Imperial Valley 1940 seismic excitation with maximum acceleration $\left(\alpha_{\max }\right)$ scaled to be equal to the design acceleration of 


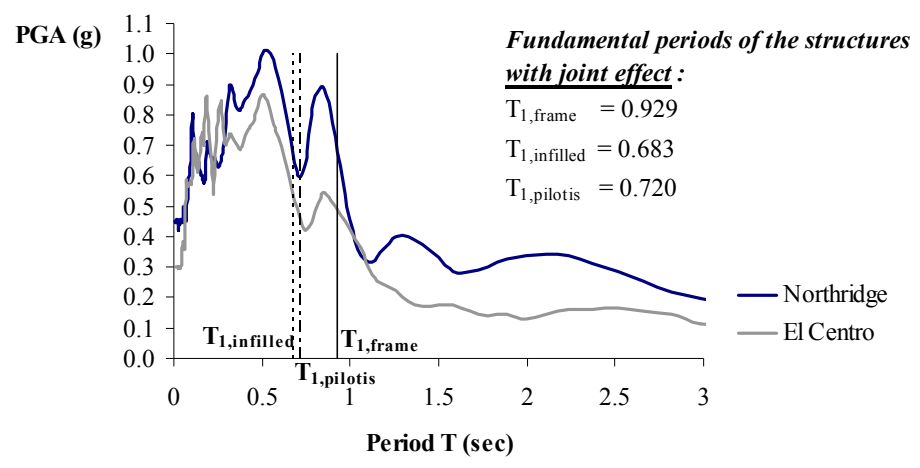

Figure 6: Elastic response spectra of the selected earthquake records and fundamental periods of the structures with joint damage effect.

the examined structure $\left(\alpha_{\max }=0.3 g\right)$ and (b) Northridge, USA 1994 seismic excitation with $\alpha_{\max }=0.45 \mathrm{~g}$.

No safe conclusion can be drawn about the influence of the exterior joints damages on the maximum demands for ductility of the critical column that suffers the hit. Critical is proved to be the influence of the pounding on the seismic response of the exterior beam-column joints at the floor levels where the interaction takes place (Fig. 7(a)). In any case, the interaction between the structural systems caused an increase on the demands for inelastic response of the joints of the multistory frame structures in comparison to the corresponding requirements without considering the pounding effect.

\section{Influence of infills on the pounding problem}

Considering that masonry infills substantially change the dynamic characteristics of the reinforced concrete structures [31], the influence of masonry infill panels on the seismic response of the critical column of the multistory structure and on the seismic response of the exterior joints that suffers the pounding effect has also been included taken into account three types of infilled multistory structures: (a) bare frame structure (without infills), (b) fully infilled structure and (c) infills are considered in the 2nd-8th stories and thus soft 1 st story (pilotis type building). For comparison reasons the response of the infilled multistory frame structures is also studied without the joints damage effect. The results are focused on the local response of the critical column of the RC multistory structure that suffers the hit from the slab of the adjacent shorter structure. Further, the exterior joints local response and the local response of the infills due to the pounding effect were studied.

The developing maximum rotational requirements of the exterior joints are significantly reduced in cases that masonry infills are taken into account. This is not the case of pilotis type structure (soft story) where due to the pounding effect high level of rotational deformations demands were concentrated in the core area of the exterior joint at the contact floor level (4th floor) (Fig. 7). 
12 Earthquake Resistant Engineering Structures X

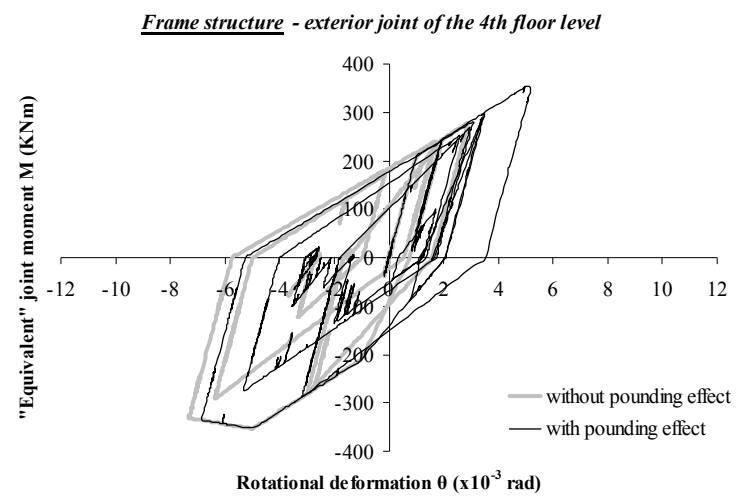

(a)

Infilled frame structure - exterior joint of the 4th floor level

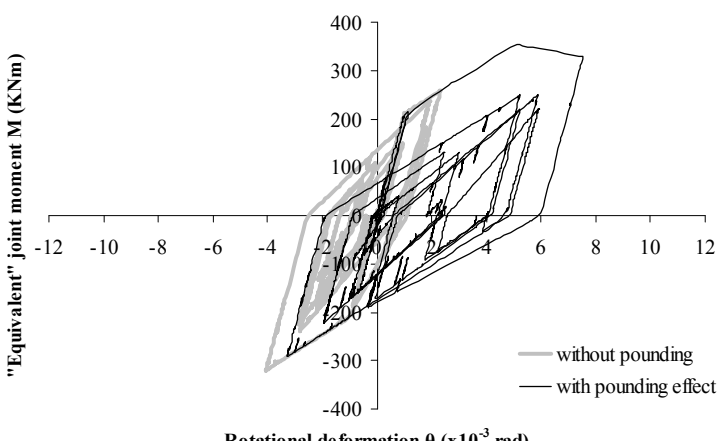

(b)

Pilotis frame structure - exterior joint of the 4th floor level

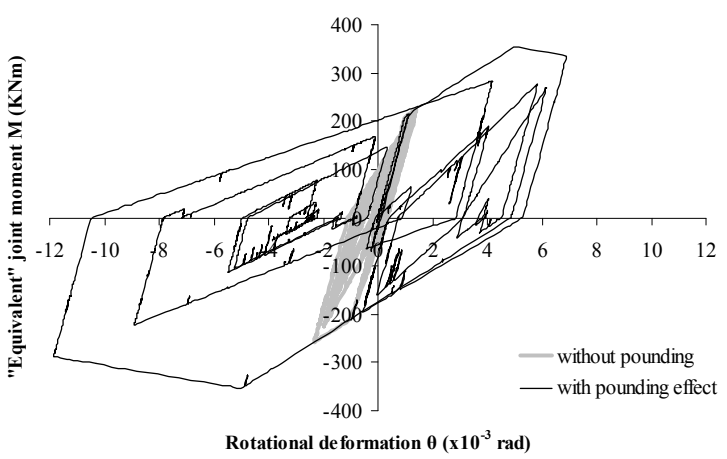

(c)

Figure 7: Influence of the inter-story pounding on the hysteretic response of the exterior joint of the 4th floor level of the tall RC structures in the area of the impact. 
The presence of infills led in all cases to an increase of the demands for shear and ductility of the critical column that suffers the impact, when compared to the corresponding demands that were developed in the cases that the multistory frame is studied without considering the infills (Figs 8 and 9).

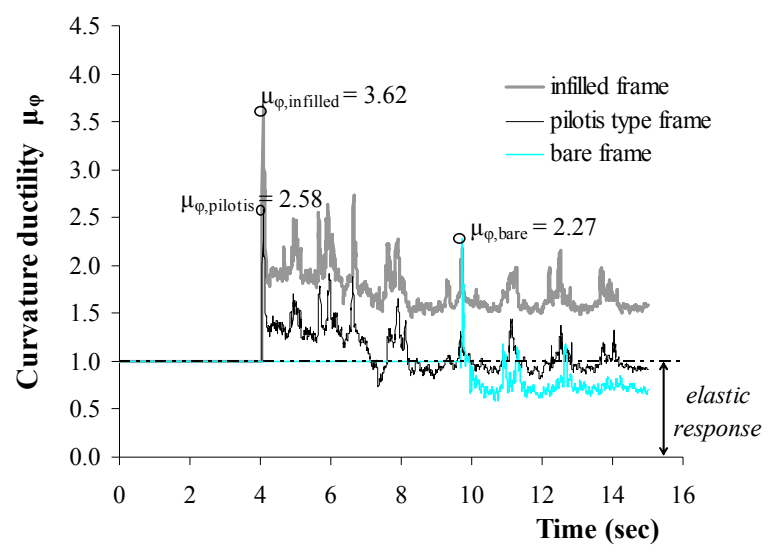

Figure 8: Inter-story pounding effect for the examined cases that include masonry infill panels.Time history ductility requirements of the external column of the 4th story that suffers the hit (interaction at $\mathrm{h}_{\mathrm{A}}=1 / 3 \mathrm{~h}$ with $\mathrm{d}_{\mathrm{g}}=0.0$ ).

The case of pilotis type structure was proved to be the most critical one for the seismic performance of the column that suffers the hit and for the exterior joint in the area of the impact in terms of shear and inelastic deformation demands, respectively.

Finally, Figure 10 comprises the influence of the structural inter-story pounding on the local response of the masonry infills. The results are for two types of infilled frames; (a) fully infilled, and (b) pilotis type. Comparative results in terms of maximum developed deformations of the infill panels are presented between the cases that (a) the structural system suffers the inter-story pounding effect and (b) the structures are vibrating independently (without interaction effect). In this figure the capacity deformation at ultimate strength of the infills as well the ultimate deformation at failure are shown.

It is clearly deduced that the seismic performance of the infills substantially changes due to pounding effect. Failure of the infills of the 8-story structures is observed at the floors above the level of the contact (4th floor) in comparisons with the ones of the same frames without the inter-pounding effect.

\section{Seismic assessment of RC structures with pounding problems}

An important issue in the field of the structural engineering is the assessment of the seismic performance of the RC structures under strong ground motions while 

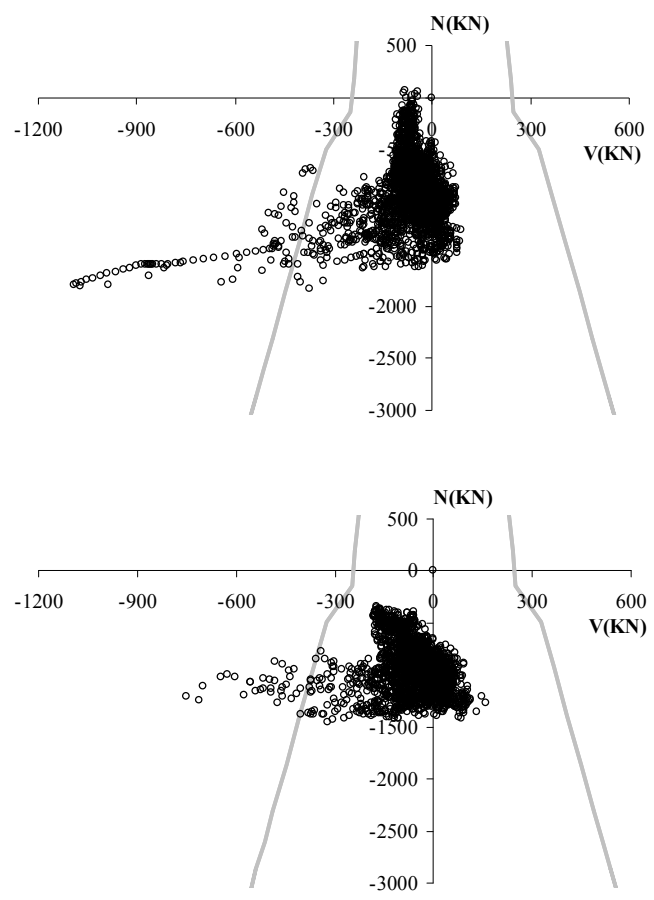

Shear strength

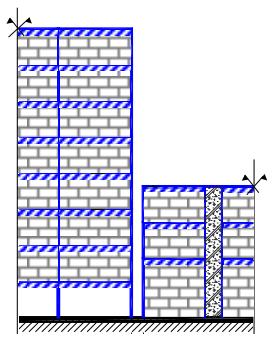

(a) Pilotis type frame

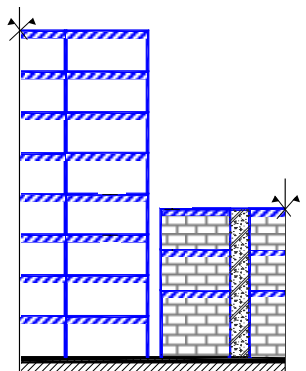

(b) Bare frame

- Requirements

Figure 9: Influence of the infill panels on the pounding problem of the 8-story $\mathrm{RC}$ frame structure. Developing shear forces of the external column of the 4th story that suffers the inter-story pounding.

the inter-story pounding between adjacent structures has been recognized as the most crucial case of interaction for the integrity of the structural stability.

Nevertheless, in the modern seismic design codes there are no provisions to ensure the column that may be suffer the impact effect from critical increase of the flexural and shear capacity requirements. Also, code's limits for adequate gap distances between the adjacent RC structures are not directly incorporated with the seismic hazard level and the local capacities of the columns that suffer the inter-story pounding effect.

Recently, the seismic assessment of adjacent RC structures with interaction problems at different limit states and different levels of seismic hazard has been studied by Favvata et al. [29] and Favvata [30]. Based on these initial results, the following key issues have been raised:

The column that suffers the impact appears to be in critical condition due to high ductility demands when the limit state of the assessment is altered from damage limitation to significant damage or to near collapse (Fig. 11). 


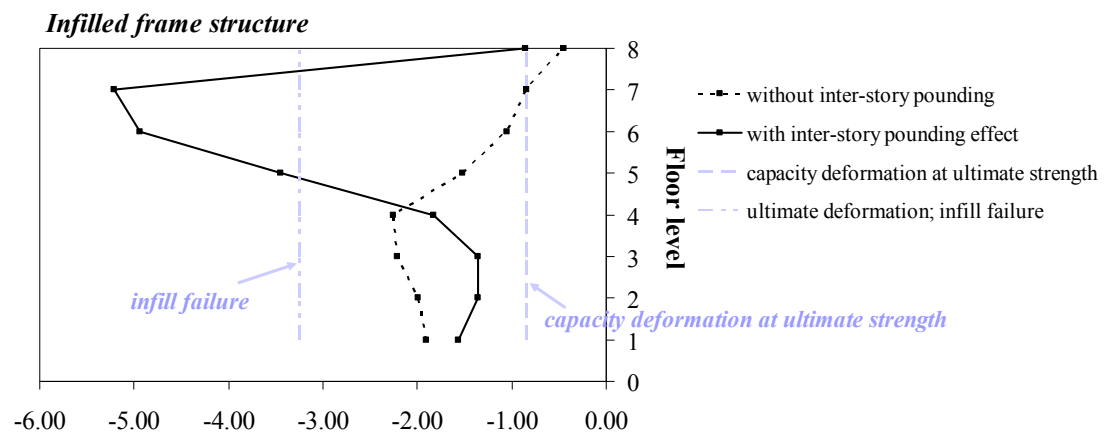

Maximum deformation of diagonal strut (infill panel $)(\%$ )

\section{Pilotis type frame structure}

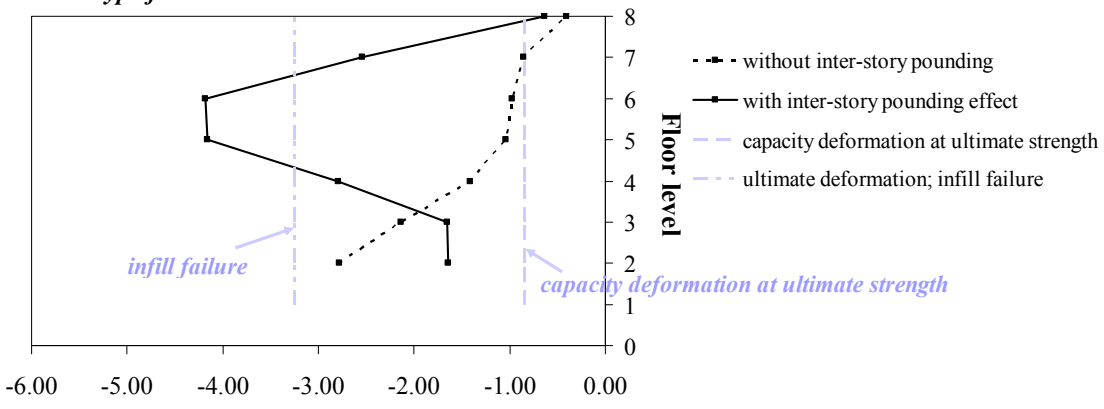

Maximum deformation of diagonal strut (infill panel) $(\%$ )

Figure 10: Influence of the inter-story pounding on the maximum developed deformations of the infills (interaction at $h_{A}=1 / 3 h$ with $d_{g}=0.0$ ).

Ductility requirements of the column that suffers the impact

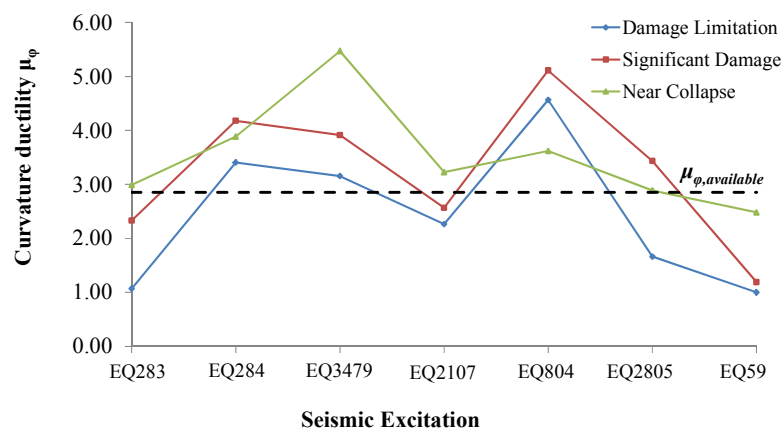

Figure 11: Maximum curvature ductility requirements of the column of the 8story RC frame structure that suffers the hit at three different limit states. 
The column that suffers the hit is always in a critical condition due to shear action. The level of the seismic intensity (low, medium or high level of seismic hazard) influences the number of times the shear demand of the column exceeds the corresponding available strength during the analysis [30]. The minimum gap distance that is required between adjacent RC structures in order to eliminate the possibility for interaction seems to depend on the limit state and the level of the seismic hazard that is used for the evaluation (Fig. 12).

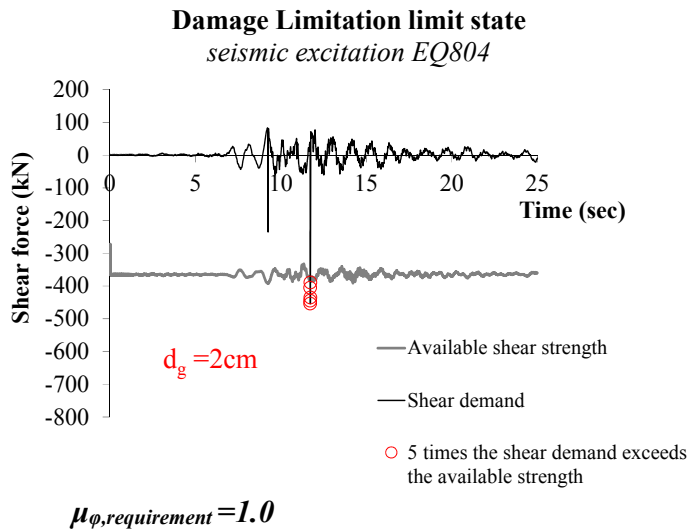

(a)

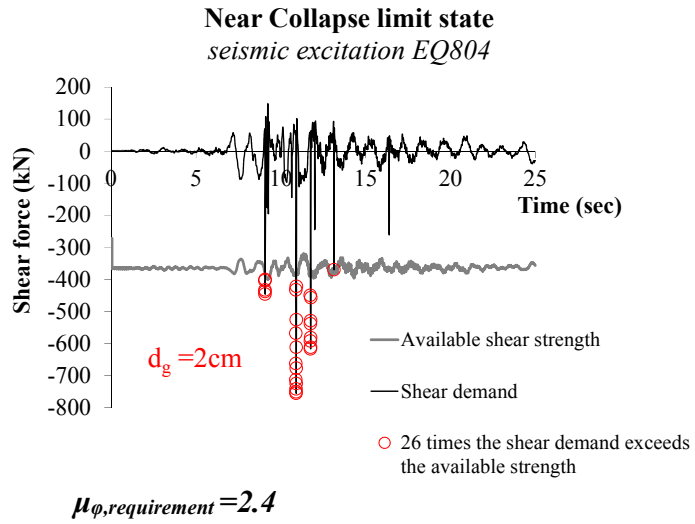

(b)

Figure 12: Gap distances between the adjacent RC structures to prevent the critical shear demands of the critical column of the tall RC structure that suffers the hit.

Although, Eurocode's provisions for adequate gap separation do not depend on the seismic demand (limit state) in the case of low level of seismic hazard these provisions seem to be conservative. Nevertheless, in this direction further investigation is required. 


\section{Concluding remarks}

In this study key parameters of the structural pounding problem and their influence on the ductility and shear requirements of reinforced concrete (RC) structures with different story heights were presented and the following remarks are noted:

- The most critical interaction case for the seismic performance of the RC multistory structures is that of the inter-story pounding where the slabs of the short stiffer structure hit the columns of the other structure at a point within the deformable height.

- A gap distance separation between the adjacent structures decreases drastically the ductility demands of the columns that suffer the hit but it is not equally effective in decreasing the developing shear forces due to the pounding.

- High difference between the heights of the adjacent RC structures decreases the demands for ductility and shear strength of the columns that suffer the hit.

- It seems that the presence of infills increases demands for shear and ductility capacity of the critical columns that suffer the impact.

- The demands for inelastic response of the exterior RC beam-column joints of the tall multistory structures are critically increased at the floor levels where the interaction takes place.

- Premature failure of the infills of the multistory RC structures is expected at the floors above the level of the contact due to the inter-story pounding effect.

The seismic assessment of RC structures with pounding problems pointed out the following issues:

(a) The minimum gap distance between the adjacent structures that is required in order to eliminate the shear demands of the column that suffers the hit seems to depend on the limit state and the level of the seismic hazard that is used for the evaluation.

(b) In any case the column that suffers the hit is always in a critical condition due to shear action. The level of the seismic intensity (seismic hazard) influences the number of times the shear demand of the column exceeds the corresponding available strength during the analysis.

(c) The column that suffers the impact appears to be in critical condition due to high ductility demands when the limit state of the assessment is altered from damage limitation to significant damage or to near collapse.

\section{References}

[1] Arnold, C. \& Reitherman, R., Building Configuration \& Seismic Design. John Wiley \& Sons, 1982.

[2] Rosenblueth, E. \& Meli, R., The 1985 Earthquake: Causes and Effects in Mexico City. Concrete International ACI, 8(5), pp. 23-24, 1986.

[3] Bertero, V.V., Observations on structural pounding. Proc. Intern. Conf. Mexico Earthquakes ASCE, pp. 264-287, 1986. 
[4] Jeng, V. \& Tzeng, W.L., Assessment of seismic pounding hazard for Taipei City. Engineering Structures, 22, pp. 459-471, 2000.

[5] Anagnostopoulos, S.A. \& Spiliopoulos, K.V., An Investigation of Earthquake induced pounding between adjacent Buildings. Earthquake Engineering and Structural Dynamics, 21, pp. 289-302, 1992.

[6] Papadrakakis, M., Mouzakis, H., Plevris, N. \& Bitzarakis, S., A Langrange multiplier solution method for pounding of buildings during earthquakes. Earthquake Engineering and Structural Dynamics, 20, pp. 981-998, 1991.

[7] Maison, B.F. \& Kasai, K., Analysis for type of Structural Pounding. Structural Engineering ASCE, 116(4), pp. 957-977, 1990.

[8] Chau, K.T. \& Wei, X.X., Poundings of structures modeled as non-linear impacts of two oscillators. Earthquake Engineering and Structural Dynamics, 30, pp. 633-651, 2001.

[9] Karayannis, C.G. \& Fotopoulou, M.G., Pounding of multistory RC structures designed to EC8 \& EC2. Proc. of the $11^{\text {th }}$ European Conference on Earthquake Engineering, Balkema, ISBN 905410982 3, 1998.

[10] Rahman, A.M., Carr, A.J. \& Moss, P.J. Seismic Pounding of a Case of Adjacent Multiple-Storey Buildings of differing total Heights considering Soil Flexibility Effects. Bulletin of the New Zealand Society for Earthquake Engineering, 34(1), pp. 40-59, 2001.

[11] Kim, S.-H., Lee, S.-W. \& Mha, H.-S., Dynamic behaviors of the bridge considering pounding and friction effects under seismic excitations. Structural Engineering and Mechanics, 10, pp. 621-633, 2000.

[12] Ruangrassamee, A. \& Kawashima K., Control of nonlinear bridge response with pounding effect by variable dampers. Engineering Structures, 25, pp. 593-606, 2003.

[13] Karayannis, C.G. \& Favvata, M.J., Earthquake-induced interaction between adjacent reinforced concrete structures with non-equal heights. Earthquake Engineering and Structural Dynamics, 34(1), pp. 1-20, 2005a.

[14] Karayannis, C.G., \& Favvata, M.J., Inter-story pounding between multistory reinforced concrete structures. Structural Engineering and Mechanics, 20(5), pp. 505-526, 2005 b.

[15] Favvata, M.J., Karayannis, C.G. \& Liolios, A.A., Influence of exterior joint effect on the inter-story pounding interaction of structures. Structural Engineering and Mechanics, 33(2), pp. 113-136, 2009.

[16] Favvata, M.J. \& Karayannis, C.G., The inter-story pounding effect on the seismic behavior of infilled and pilotis RC structures. Geotechnical, Geological and Earthquake Engineering, 24, pp. 87-101, 2013.

[17] Favvata, M.J., Karayannis, C.G. \& Anagnostopoulou, V., Influence of infill panels with and without openings on the pounding effect of RC structures. Proc. of the 15th World on Earthquake Engineering, Lisbon Portugal, pp. 24-28, 2012.

[18] Favvata, M.J., Naoum, M.C. \& Karayannis, C.G., Earthquake induced Earthquake induced interaction between $\mathrm{RC}$ frame and steel frame 
structures. WIT Transactions on the Built Environment, 134, pp. 839-851, 2013.

[19] Anagnostopoulos, S.A. \& Karamaneas, C.E., Use of collision shear wall to minimize seismic separation and to protect adjacent buildings from collapse due to earthquake-induced pounding. Earthquake Engineering and Structural Dynamics, 37(12), pp. 1371-1388, 2008.

[20] Abdel Raheem, S.E., Pounding mitigation and unseating prevention at expansion joints of isolated multi-span bridges. Engineering Structures, 31(10), pp. 2345-2356, 2009.

[21] Cole, G.L., Dhakal, R.P., Carr, A.J. \& Bull, D.K., Building Pounding State of the Art: Identifying Structures Vulnerable to Pounding Damage. New Zealand Society for Earthquake Engineering Annual Conference, New Zealand, P11, 2010.

[22] Pant, D.R. \& Wijeyewickrema, A.C., Structural performance of a baseisolated reinforced concrete building subjected to seismic pounding. Earthquake Engineering and Structural Dynamics, 41(12), pp. 1709-1716, 2012.

[23] Efraimiadou, S., Hatzigeorgiou, G.D. \& Beskos, D.E., Structural pounding between adjacent buildings subjected to strong ground motions: Part I: The effect of different structures arrangement. Earthquake Engineering and Structural Dynamics, 42 (10), pp. 1509-1528, 2013.

[24] Naserkhaki, S., El-Rich, M., Aziz, F.N.A.A. \& Pourmohammad, H., Pounding between adjacent buildings of varying height coupled through soil. Structural Engineering and Mechanics, 52(3), pp. 573-593, 2014.

[25] Moustafa, A. \& Mahmoud, S., Damage assessment of adjacent buildings under earthquake loads. Engineering Structures, 61, pp. 153-165, 2014.

[26] Jankowski, R., Seleemah, A., El-Khoriby, S. \& Elwardany, H., Experimental study on pounding between structures during damaging earthquakes. Key Engineering Materials, 627, pp. 249-252, 2015.

[27] Favvata, M.J., Izzuddin, B.A. \& Karayannis, C.G., Modelling exterior beam-column joints for seismic analysis of RC frame structures. Earthquake Engineering and Structural Dynamics, 37(13), pp. 1527-1548, 2008.

[28] Paulay, T. \& Priestley, M.J.N., Seismic design of reinforced concrete and masonry buildings. John Wiley \& Sons, 1992.

[29] Favvata, M.J., Mochla S.E., Naoum, M.C. \& Karayannis, C.G., Assessment of multistory RC buildings suffering inter-story pounding. Proc. of the 5th ECCOMAS, Thematic Conference on Computational Methods in Structural Dynamics and Earthquake Engineering, Crete Island, Greece, 2015.

[30] Favvata, M.J., Interaction of adjacent multistory RC frames at significant damage and near collapse limit states. WIT Transactions on the Built Environment, Vol 152, WIT Press, 2015.

[31] Kakaletsis, D., Karayannis, C. Experimental investigation of infilled r/c frames with eccentric openings. Structural Engineering and Mechanics, 26(3), pp. 231-250, 2007. 